\title{
DIFFERENTIATION OF SELF AND FUNCTIONING IN A CLOSE RELATIONSHIP - RESULTS OF STUDIES CONDUCTED IN POLAND
}

\author{
Boguslawa Lachowska \\ Institute of Psychology, John Paul II Catholic University, Lublin (Poland)
}

\begin{abstract}
The concept of differentiation of self occurring in the M. Bowen theory expresses an interpersonal capability of an individual for maintaining closeness with others, without the loss of autonomy of own self. The objective of the presentation is to show experiences associated with analysis of the construct on the Polish ground. The study included 538 respondents. The results of a two-stage hierarchical multiple regression showed that the greater the trust in a partner in a close relationship, the lower the tendency towards the emotional cut-off and a greater tendency towards assuming the 'I' Position. The level of intimacy in a close relationship is higher, whereas a lower tendency towards the emotional cut-off, the higher the individual's emotional reactivity, as well as a greater tendency towards assuming the 'I' Position. The results of correlation analyses showed that the greater the tendency towards assuming the 'I' Position and the lower the tendency towards the emotional cut-off, the higher the scores according to the scales of balanced adaptability and cohesion dimensions in family interactions, the better the family communication, whereas the greater tendency towards the emotional cut-off, the higher the scores on the disengaged subscale. Relationships were examined between differentiation of self, and the individual's attachment styles: secure, avoidant, fearful-ambivalent.
\end{abstract}

Keywords: Differentiation of self, close relationship, intimacy, interpersonal trust, attachment styles.

\section{Introduction}

Differentiation of self (DoS) is the main concept of the Bowen family system theory (1978; Kerr and Bowen, 1988). According to this theory, two levels of DoS are distinguished: interpersonal and intrapersonal. DoS on the intrapersonal level concerns the ability of an individual to distinguish between feelings and thoughts, and balance emotional and intellectual functioning. DoS on the interpersonal level concerns the abilities of an individual to experience closeness with others, without the loss of autonomy of own self (Kerr \& Bowen, 1988). In this theory, at least four indicators of the level of differentiation of an individual are adopted: the ability to take an "I"-Position (IP), the emotional reactivity (ER), emotional cut-off (EC) and the fusion with others (FO) (Skowron \& Friedlander, 1998; Skowron \& Schmitt, 2003).

The concept of differentiation of self allows prediction of the functioning of an individual. In the studies conducted to-date it has been found that - in accordance with Bowen's theory - a higher level of $\mathrm{DoS}$ is associated with a lower number of somatic and mental health disorders (Rodríguez-González \& Schweer-Collins \& Skowron \& Jodar \& Cagigal de Gregorio \& Major, 2019; Skowron \& Friedlander, 1998), and a higher marital satisfaction (Peleg, 2008).

\section{Objectives}

The aim of the study is investigation of the relationship between the level of DoS and the functioning of an individual in a close romantic relationship. Trust in the partner in a relationship and intimacy in the relationship were taken into account. The subsequent goal is examination of the relationship between the level of DoS and the attachment style of an individual, as well as between the level of DoS and cohesion and flexibility of intrafamiliar relations and intra-family communication in the family of origin.

\section{Methods}

The study included a total number of 538 respondents in four groups: persons remaining in a romantic relationship $(\mathrm{n} 1=166 ; 505$ females, mean age $\mathrm{M}=33.28, \mathrm{SD}=6.96)$, 84 married couples $(\mathrm{n} 2=168$ persons, mean age $\mathrm{M}=32.01, \mathrm{SD}=5.43)$, females remaining in a romantic relationship 
$(\mathrm{n} 3=100$, mean age $\mathrm{M}=25.40, \mathrm{SD}=4.14)$, students $(\mathrm{n} 4=104,53 \%$ of females, aged 18-26). Differentiation was determined using the Differentiation of Self Inventory-Revised DSI-R (Skowron and Schmitt, 2003) (first and third study), and the Differentiation of Self Inventory DSI (Skowron \& Friedlander, 1998) (second and fourth study). Trust in the partner in a close romantic relationship was measured by means of the Polish version (Lachowska, 2019) of the Trust Scale (Rempel, Holmes, Zanna, 1985), intimacy in the relationship was assessed using the Personal Assessment of Intimacy in Relationships (Schaefer, Olson, 2007). Family interactions were determined by means of the Polish version (Lachowska, 2008) of The Family Adaptability and Cohesion Scale (Olson, Gorall, Tiesel, 2006). Attachment style was assessed using the Attachment Style Questionnaire (Plopa, 2005). Analysis of the data was performed using the IBM SPSS Statistics 25 statistical package. In order to define the predictors of the intimacy in a close relationship and the trust in the partner, hierarchical multiple regression analysis was conducted, allowing control of the influence of a group of independent variables on the dependent variable, and helping to decide whether adding a particular set of variables significantly enhances the statistical quality of a prediction in proportion to the typical ones in the field of predictors. A series of two-stage hierarchical multiple regressions were performed, first with interpersonal trust and then with the intimacy of close relationships. The first stage of the regression included the demographic variables. The four indices of differentiation of self (IP, ER, EC, FO) were entered at stage two. In addition, the correlation between the variables was analyzed ( $r$ Pearson's correlation coefficient).

\section{Results}

\subsection{Differentiation of self and trust in the partner in a romantic relationship and intimacy of the relationship}

A two-stage hierarchical multiple regression was conducted with trust in the partner as the dependent variable. The first stage of the regression included relationship of duration and type of relationship (marriage/common-law marriage). Analyses revealed that, at stage one, relationship duration $(\beta=-0.31 ; p<0.01)$ contributed significantly to the regression model. Together, the two independent variables accounted for $6 \%$ of the variation in trust. Introducing the DoS variables explained an additional $31 \%$ of variation in trust, and this change in $R^{2}$ was significant $(p<0.001)$. When all six independent variables were included in stage two of the regression model, the significant predictors of the trust were: the result according to the EC scale $(\beta=0.39 ; p<0.00)$, IP $(\beta=0.27 ; p<0.05)$ and relationship duration $(\beta=-0,31 ; p<0.01)$. Together, the six independent variables accounted for $37 \%$ of the variation in trust in the partner. A set of two-stage hierarchical multiple regression was conducted with global intimacy, and subsequently with its individual dimensions (emotional, intellectual, social and sexual intimacy) as the dependent variable. The first stage of the regression included gender, relationship duration, possession of children. Analyses revealed that, at stage one, in any case demographic variables did not contribute significantly to the regression model. Introducing the DoS variables explained an additional $45 \%$ of variation in global intimacy, and this change in $R^{2}$ was significant. When all seven independent variables were included in stage two of the regression model, the significant predictors of the global intimacy were EC $(\beta=0.67 ; p<0.00)$, IP $(\beta=0.23 ; p<0.001)$ and ER $(\beta=-0.22 ; p<0.05)$. Together, the seven independent variables accounted for $46 \%$ of the variation in global intimacy. The hierarchical multiple regression with emotional intimacy as a dependent variable revealed that introducing DoS variables explained an additional $24 \%$ of variation in emotional intimacy, and this change in $R^{2}$ was significant. When all seven independent variables were included in stage two of the regression model, the significant predictors of the emotional intimacy were only $\mathrm{EC}(\beta=0,53 ; p<0.001)$. Together, the seven independent variables accounted for $26 \%$ of the variation in emotional intimacy. The hierarchical multiple regression with intellectual intimacy as a dependent variable revealed that introducing the DoS variables explained an additional $27 \%$ of variation in intellectual intimacy, and this change in $R^{2}$ was significant. When all seven independent variables were included in stage two of the regression model, the significant predictors of the intellectual intimacy were $\mathrm{EC}(\beta=0.44 ; p<0.001)$ and IP $(\beta=0.26 ; p<0.001)$. Together, the seven independent variables accounted for $27 \%$ of the variation in intellectual intimacy. The hierarchical multiple regression with social intimacy as a dependent variable revealed that introducing the DoS variables explained an additional $18 \%$ of variation in social intimacy, and this change in $R^{2}$ was significant. When all seven independent variables were included in stage two of the regression model, the significant predictors of social intimacy were only EC $(\beta=0.43 ; p<0.001)$. Together, the seven independent variables accounted for $23 \%$ of the variation in social intimacy. The hierarchical multiple regression with sexual intimacy as a dependent variable revealed that introducing the DoS variables explained an additional 34\% of variation in sexual intimacy, and this change in $R^{2}$ was significant. When all seven independent variables were included in stage two of the regression model, the significant predictors of the sexual intimacy were IC $(\beta=0.58 ; p<0.001)$, IP $(\beta=0.30 ; p<0.001)$ and ER $(\beta=-0.28 ; p<0.01)$. Together, the seven independent variables accounted for $46 \%$ of the variation in global intimacy. 


\subsection{Relationship between cohesion and flexibility of the relationship in the family of origin and attachment style, and the respondents' differentiation of self}

Analyses of correlations using Pearson's a correlation coefficient $r$ showed that balanced cohesion and balanced flexibility in the family of origin of the examined students were related with the result according to the EC scale $(r=0.30 ; p<0.01 ; r=0.25 ; p<0.01$, respectively) and the IP scale $(r=0.31 ; p<0.01 ; r=0.21 ; p<0.01$, respectively), as well as the FO scale $(r=-0.26 ; p<0.01$; $r=-0.17 ; p<0.1$, respectively). Disengagement was related with the result according to the EC scale $(r=-0.30 ; p<0.01)$ and the FO $(r=0.40 ; p<0.001)$. Good family communication was related with the result on the IP scale $(r=0.21 ; p<0.05)$; EC $(r=0.39 ; p<0.001)$ and the FO $(r=-0.20 ; p<0.05)$. Secure attachment in the examined students was related with the result according to the IP $(r=0.43$; $p<0.001)$ and FO $(r=-0.20 ; p<0.05)$. Avoidant style was related with the result according to the IP scale $(r=-0.56 ; p<0.001)$ and the FO $(r=0.28 ; p<0.01)$. Fearful-ambivalent style was related with the result according to the ER $(r=-0.32 ; p<0.001)$; the EC $(r=-0.29 ; p<0.01)$ and the IP scale $(r=-0.31$; $p<0.001)$.

\section{Discussion/conclusions}

The strongest predictor of the functioning of the respondents in a close relationship was the lack of emotional cut-off, which favours trust in the partner and perception of the relationship with this partner as more intimate (from the aspect of emotional, social, intellectual and sexual intimacy). In addition, trust in the partner and the perceived intellectual intimacy with this partner are higher, the greater the tendency to assume ' $I$ ' position. The result is interesting in that it indicates that a greater sexual intimacy was also related with a higher emotional reactivity, which - contrary to expectations - could indicate a negative effect of low emotional reactivity with respect to specific situations associated with sexual relationship. Moreover, it was found that positive experiences associated with relationships within the family of origin were related with a higher level of differentiation of self. According to the concept of family systems by Olson, balanced cohesion and balanced flexibility are related with higher, whereas unbalanced cohesion (disengagement) with lower differentiation of self in young persons growing in a family. A higher differentiation is related with secure style, while a lower differentiation - with insecure styles (fearful-ambivalent and avoidant).

\section{References}

Bowen, M. (1978). Family therapy in clinical practice. Northvale, NJ: Jason Aronson, Inc.

Kerr, M. E., \& Bowen, M. (1988). Family evaluation: An approach based on Bowen theory. New York: Norton \& Co.

Lachowska B. (2008). Rodzina jako system społeczny w ujęciu Modelu Kołowego Systemów Małżeńskiego i Rodzinnego opracowanego przez D.H. Olsona i współpracowników oraz narzędzia pomiaru. Roczniki Teologiczne, Zeszyt Instytutu Nauk o Rodzinie, Tom LV, zeszyt 10, 189-206.

Lachowska B. (2019). The Polish version of the Trust Scale: Preliminary validation. The Review of Psychology (in print).

Olson, D.H. \& Gorall, D.M. \&Tiesel, J.W. (2006). FACES IV Package. Administration Manual. Minneapolis: Life Innovation.

Peleg, O. (2008). The Relation Between Differentiation of Self and Marital Satisfaction: What Can Be Learned from Married People Over the Course of Life? The American Journal of Family Therapy, $36: 5,388-401$.

Rempel, J. K., Holmes, J. G., \& Zanna, M. P. (1985). Trust in close relationships. Journal of Personality and Social Psychology, 49(1), 95-112.

Rodríguez-González, M. \& Schweer-Collins, M. \& Skowron, E. A. \& Jodar, R. \& Cagigal de Gregorio, V. \& Major, S.O. (2019). Stressful Life Events and Physical and Psychological Health: Mediating Effects of Differentiation of Self in a Spanish Sample. Journal of Marital and Family Therapy, Oct;45(4):578-591. doi: 10.1111/jmft.12358. Epub 2018 Sep 21.

Schaefer, M. \& Olson, D. (2007). Assessing intimacy: The PAIR inventory. Journal of Marital and Family Therapy. 7:47 - 60 .

Skowron, A.E. \& Schmitt, A.T. (2003). Assessing interpersonal fusion: Reliability and validity of a new DSI fusion with others subscale. Journal of Marital and Family Therapy, 29, 209-222.

Skowron, E. A., \& Friedlander, M. L. (1998). The Differentiation of Self Inventory: Development and initial validation. Journal of Counseling Psychology, 45(3), 235-246. 